\title{
3D MODELLING OF ARCHITECTURAL BLOCKS AND ANTIQUE SCULPTURES FOR THE CONSERVATION AND THE PROMOTION OF ARCHAEOLOGICAL HERITAGE - EXPERIMENTS IN ALSACE
}

\author{
M. Koehl ${ }^{1, *}$, M. Fuchs ${ }^{2}$ \\ ${ }^{1}$ INSA Strasbourg / ICube UMR 7357 - Engineering science, computer science and imaging laboratory - Remote Sensing, \\ Radiometry and Optical Imagery Group - mathieu.koehl@insa-strasbourg.fr \\ 2 Archéologie Alsace - matthieu.fuchs@archeologie.alsace
}

\section{Commission II, WG II/8}

KEY WORDS: Archaeological blocks, Antique sculptures, 3D modelling, Processing, Photogrammetry, Dense matching

\begin{abstract}
:
This paper presents the results of several studies led on the 3D modelling of blocks by photogrammetry. These blocks are constitutive elements of vestiges of buildings and tombs from the Roman period. A first series of blocks are a part of a mausoleum, a second are parts of tombs, and a last series are part of an antique theatre. The 3D modelling has been undertaken to get the maximum of 3D knowledge elements for the virtual reconstruction, in particular of the mausoleum. As the theatre is still not perfectly identified, the blocks served as 3D geometrical base for a more advanced archaeological study. The 3D modelling of these blocks allowed to sum-up the processing chain used for the first types of blocks and to adapt it to particular conditions of data acquisition.
\end{abstract}

\section{INTRODUCTION}

\subsection{Context of study}

The Archéologie Alsace (2019) public Institution carries out archaeology missions throughout the Alsatian territory (NorthEast of France), on all the components of archaeology: inventory of preserved archaeological sites and collections, advice to developers, preventive archaeology (diagnostics and excavations), conservation and restoration of archaeological objects, development of sites and monuments, scientific research and dissemination, cultural mediation to all audiences. The nature of these missions regularly confronts archaeologists and specialists with problems of data acquisition, processing and enhancement, which can take on a new dimension with digital technologies in general and 3D modelling in particular. In order to change practices, adapt to new technologies and provide more relevant responses to these problems, a partnership has been established with the National Institute of Applied Sciences in Strasbourg, to experiment and develop more relevant acquisition and modelling methods. The examples discussed here relate to blocks of Gallo-Roman architecture from three different sites and contexts.

\subsection{Description of the sites}

1.2.1 Architectural blocks and the ancient monument of the Meisenbachschloessel in Sparsbach (Bas-Rhin / Alsace / France)

The Meisenbachschloessel is a monumental Gallo-Roman building located in the Vosges du Nord forest. It is placed on a rocky spur overlooking the confluence of two streams and a spring, which form a modest tributary of the Moder, river that joins the Rhine north of Strasbourg. This antique building has been indicated since the beginning of the 19th century. It has the character, unique in Alsace, of a large-scale sandstone block edifice in a sandstone quarry environment that has been exploited since antiquity. Long presented as a rectangular apse building whose date, function and plan were only partially determined, the site (Figure 1) was excavated in 2005-2006 by the Department of Bas-Rhin and the University of Strasbourg. These excavations made it possible to clear the entire perimeter of the monument (13.20 x 8 meters). Its construction dates back to the High Kingdom, probably during the 2nd century, and its destruction probably after the 4th century (Fuchs and Meyer, 2019).

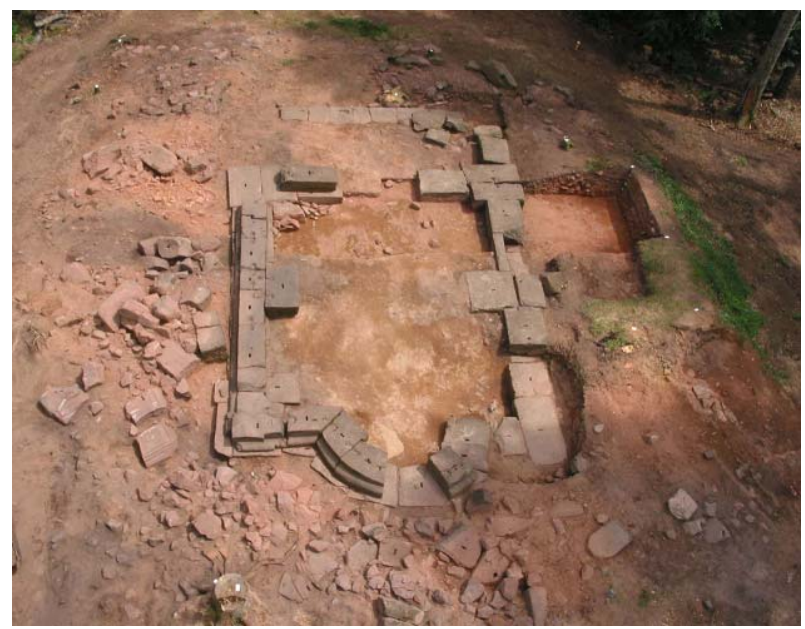

Figure 1: The monument opened during the excavations (2006)

While only foundation lines were recognized, excavations at the beginning of the 21st century uncovered several hundred blocks and fragments of architectural blocks. This situation reflects the fact that the recovery of materials had favoured simple blocks and left all the complex blocks, more difficult to reuse, on site. To carry out the excavation, the blocks had to be removed, level

* Corresponding author 
by level, and storage was arranged away from the site (Figure 4).

Typology of blocks: Nearly two hundred blocks and fragments with architectural features have been classified and stored specifically in an open air block-park, on wooden sleepers to better understand the building. Most of them have been the subject of traditional manual surveys either partially or on all the faces (Marc et al., 2005, 2006). Of very variable size and weight (from a few kilos to more than one ton) these blocks had a relatively satisfactory conservation, despite sometimes very large fragmentation. The parallelepipeds which made up the main part of the walls having been recovered, mainly remained the mouldings and cornices of crowning and framing of the monument, as well as the blocks of the arch of the apse.

These blocks present traces of tools, but also cuts useful for lifting and assembly systems. On reading the recovered blocks, the decoration was very simple, there are no trace of friezes or decorations in bas-relief, even if these elements were perhaps originally painted.

Issue and purpose of modelling: After the demolition of the monument at the end of Antiquity or the beginning of the Middle Ages, the site seems to have been quickly covered by forest vegetation and then by a layer of humus which masked the remains, but also protected them. The uncovering of the blocks and foundations therefore raises new conservation problems, the sandstone being a relatively friable and live rock. Before 2008, the archaeological soils around the monument were covered. In 2016 the decision was made to bury the blocks in the ground to protect them from bad weather and damage, but to proceed with their preliminary modelling. Landfill allows for the sustainable preservation of these remains.

High-resolution modelling now makes it possible to build a database to study blocks without having to manipulate them, and thus make the data from the blocks accessible without having to move and clear them again. It also allows for the development of new proposals and reconstitution variants (Adamopoulos et al., 2017), and the modelling of the base of the monument facilitates the production of a virtual digital model (Hayes et al., 2015), which can evolve according to hypotheses.

1.2.2 A collection of Gallo-Roman funerary headstones from Niederhergheim (Haut-Rhin / Alsace / France)

Niederghergheim is a village on the Alsatian plain, located south of Colmar and on the left bank of the Ill. In 2011, road works carried out by the Haut-Rhin Department uncovered a set of 7 monumental funerary stelae and two squared blocks at a depth of $4.30 \mathrm{~m}$, seeming to be reused to reinforce a ford passage in the middle of an old channel now filled, probably an arm or tributary of the Ill. Carved in pink sandstone (8) and yellow sandstone (1) these blocks come from antique quarries located nearby. This discovery is related to a vast complex of habitat (villa or Gallo-Roman hamlet) located less than a kilometre away.

The fortuitous nature of the discovery during road work (Figure 2) did not permit an accurate understanding of the context, but this lapidary funerary ensemble is exceptional and places the site in the 2nd place of importance of discoveries of antique stelae in the department.

Typology of blocks: The 7 funerary stelae have very large, relatively unusual sizes. 3 stelae exceed $2 \mathrm{~m}$ (max. $2.50 \mathrm{~m})$ in height and $800 \mathrm{~kg}$ (max. $895 \mathrm{~kg}$ ). 4 stelae are broken into 2 or 3 blocks, and 3 stelae are incomplete. 4 stelae present bas-reliefs sculptures representing well-preserved characters, two with crescents of the moon in the pediment and 3 stelae represent more modest bas-reliefs, also comprising crescents of the moon. The presence of a symbol of the moon is a major feature of this ensemble, which, according to the stylistic representations of the characters, is dated from the 2nd century for 6 of them, even beginning of the 3rd century for one of the stelae. The bas-relief sculptures are carved into the niches forming blocks, and 4 have epigraphic records of the deceased.

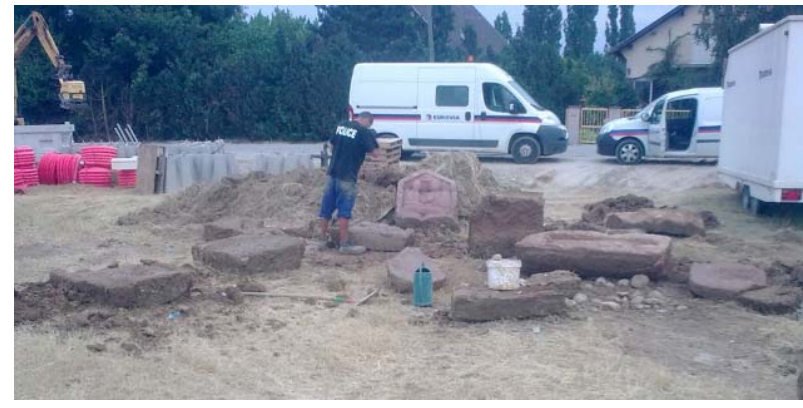

Figure 2: Incidental discovery of funerary stelae during road works

Issue and purpose of modelling: At the end of the discovery, the blocks were taken to Strasbourg where they were studied by a team led by M.-D. Waton, (Bonneterre et al., 2012). A first photogrammetric acquisition was carried out in 2012-2013 (Landes et al., 2013), but without being able to handle the blocks on all sides. In 2017, it has been decided to transfer these stelae to the Unterlinden Museum in Colmar in order to present them in Gallo-Roman collections. This transport allowed to organize a manipulation whose objective was the handling of all the faces for a complete 3D modelling. Now this data makes it possible to resume the study of stelae without having to handle very heavy blocks, but also to facilitate their restoration. In addition, the museum will be able to display only 4 of the 7 stelae, the others being kept in the reserves. Modelling will thus make it possible to make the most of the whole, for greater scientific, artistic and heritage coherence. The high resolution 3D model will also provide digital media for visitors to examine the details of the object and enrich the content elements with comparison and interpretation elements. Finally, these numerical models could be shared with specialists to develop studies of figurative representations and to promote access to researchers or to support academic work.

1.2.3 Monumental architectural blocks of the Vicus de Horbourg-Wihr (Haut-Rhin / Alsace / France)

Horbourg-Wihr is a village on the Alsatian plain, located east of Colmar on the Ill River. During ancient times, it formed an important city, with the status of Vicus of the city of the Rauraques, Gaulish people installed on the bend of the Rhine around Basel (CH). The first archaeological discoveries date back to the 16th century and the city has been regularly excavated since the end of the 20th century as part of preventive archaeology.

The ancient city, spread over more than 100 ha, consisted mainly of buildings of earth and wood architecture, only some important buildings, public and religious, have been the object of construction using the stone in elevation. Two sets of architectural blocks have recently been modelled. 
For the first set, in 2004, the excavation of the south gate of the Castellum of the 4th century, delivered architectural blocks from previous monumental civilian buildings reused in the foundations of the two towers that framed a gate of the camp. For the second set, in 1993, about twenty sandstone blocks were unearthed away from the Roman city, on a site interpreted as a medieval castle disappeared. In 2017, a first series of about ten blocks was modelled (Figure 3). On the basis of the analysis of these blocks, reinterpreted as elements of stands, and on the study of geophysical prospecting surveys, a hypothesis of the existence of a Gallo-Roman theatre prior to the castle could be proposed (Fuchs, 2019). Archaeological surveys confirmed this hypothesis and led to the digitization of the second set of blocks in 2018-19. The first field analyses make it possible to propose the constitution of a theatre on a slope in semi-circular cavea welcoming wooden bleachers, and a single row of stone bleachers, welcoming the notables who were installed as close as possible to the orchestra separating the public from the stage.

Typology of blocks: The blocks discovered in 2004 belong for two of them to cornices moulded from very large yellow sandstone apparatus while the last two correspond to a draft of stele and a simple quadratic block in pink sandstone. Their dimensions and weight greater than $800 \mathrm{~kg}$ do not allow easy manual handling.

The blocks discovered in 1993, correspond mainly to modules of stands in rectangular pink sandstone of about 0.8 to $1.3 \mathrm{~m}$ long and 30 to $40 \mathrm{~cm}$ side. All the blocks show traces of shaping techniques using several types of tools, and five of them have inscriptions that still need to be studied in depth.

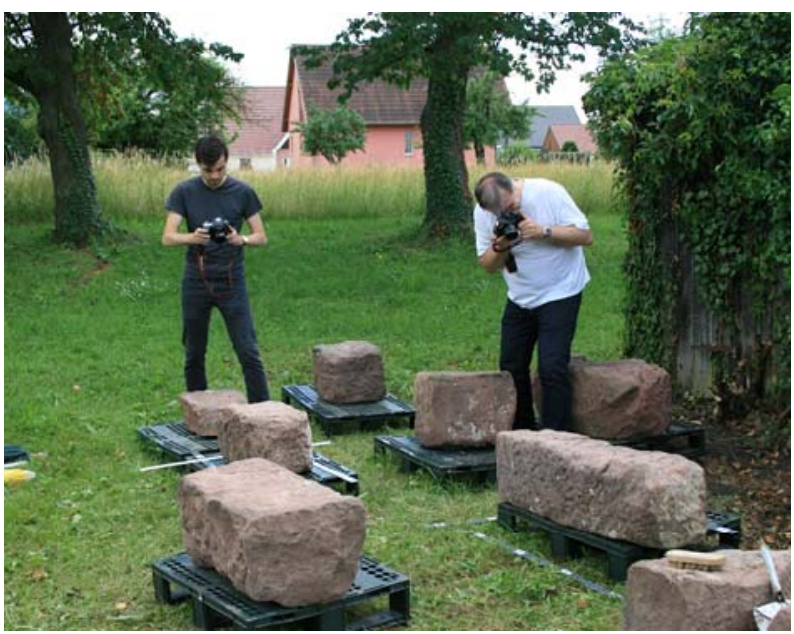

Figure 3: Photogrammetric recording in Horbourg-Wihr's block-park. Blocks stored on pallets. Use of scaling bars.

Issue and purpose of modelling: In this case, the interest of $3 \mathrm{D}$ modelling now focuses on the scientific study of the different blocks, in order to propose a functional interpretation. For blocks with inscriptions and tool marks, high resolution and image processing will allow very precise reading and in-depth interpretation.

Finally, 3D models avoid returning to the difficulties of manipulating these large blocks of architecture that can be stored and protected while waiting for a valuation by the Municipality of Horbourg-Wihr in the next few years.

\section{PHOTOGRAMMETRIC DATA ACQUISITION}

There are several methods of terrestrial photogrammetry based on the exploitation of one or more photos. Grussenmeyer (2003) lists them. It explains that multi-image bearing allows to identify complex objects where convergent, horizontal, vertical or oblique records are required. The processing consists in a bundle adjustment of blocks of images and allows to obtain a robust and homogeneous solution of the object geometry.

According to (Fuchs et al., 2004), multi-image photogrammetry, allows the reconstitution of the third dimension by the use of several points of views. He recommends following a few rules to optimize data entry. The first is to make recordings with axes approaching 90 degrees to minimize the errors. It also recommends images without masks, to perform a strong overlap between the images and avoid views with a strong effect of perspective. Indeed, the use of this technique encourages the multiplication of the images.

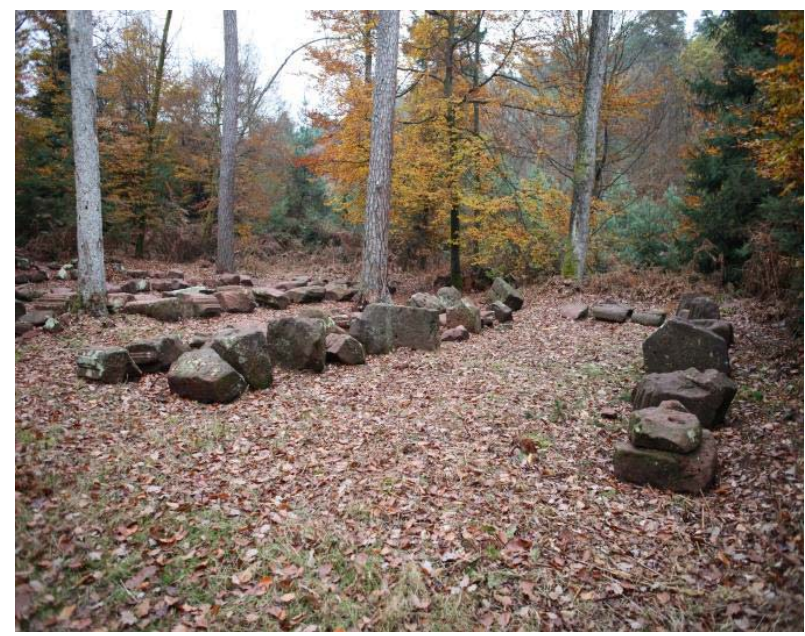

Figure 4: Block-park in Sparsbach

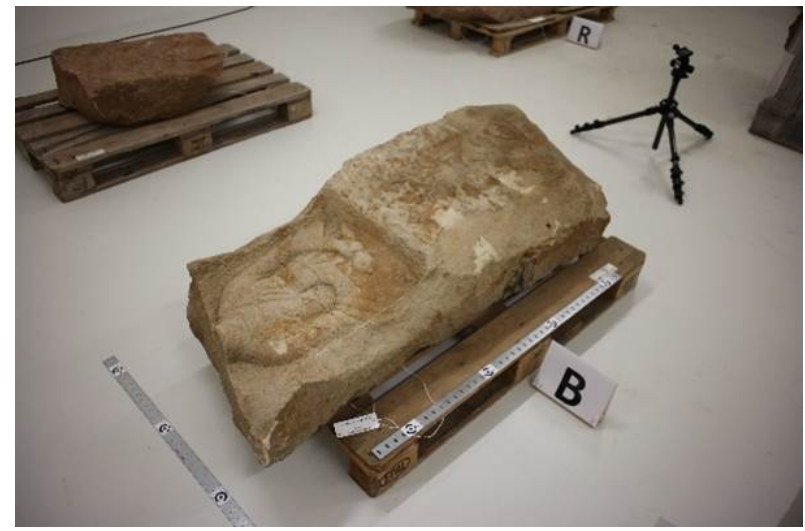

Figure 5: Acquisition environment for headstones.

The photographic equipment used was the same in all three cases. These are Canon EOS 5DS R digital cameras with image resolutions up to $50 \mathrm{Mpx}$ equipped with a $28 \mathrm{~mm}$ focal lens. The recording conditions were very different between the different sites. Indeed, while the first and last blocks were arranged in outside block-parks, the headstones were placed on pallets inside a museum's reserve offering ideal lighting conditions (Figures 4 and 5). 


\subsection{Meisenbachschloessel: a voluminous site}

The 3D modelling will be made by using photogrammetry and TLS. It was thus decided to record every block in its first position, then to record them a second time after having reversed and cleaned. The images were recorded in a convergent way, in three series (in $1.50 \mathrm{~m}$ of the ground with an angle of $45^{\circ}$, in $1 \mathrm{~m}$ of the ground with an angle of $20^{\circ}$, on the ground in the horizontal) with a high overlapping between images. Every series contains so approximately 15 to 20 images, besides complementary images of details. Every block has been identified to make the link with the former numbering (Marc, 2005 and 2006). Sometimes groups of blocks were acquired, the same series of photos covering several blocks at the same time.

The second series of recordings was made two weeks later after having reversed the blocks. These also had to be cleaned to remove the ground from it hung on for several years. The conditions of humidity were also unfavourable here. Indeed, after a long period of winter frost, undergrowth remained very wet and blocks, in rather porous sandstone were filled with humidity. Furthermore, some resting directly on the ground were soaked with humidity. The reversal and the cleaning allowed to clear them of ground residues and of vegetation, but the drying of blocks remains rather slow. So some blocks present completely different faces from the point of view of the humidity. In spite of these natural phenomena recordings were made with blocks as is. So, every block was recorded through about two series of 70 convergent images and presenting strong overlapping. The used camera is Canon EOS 5DS R with a focal length of $28 \mathrm{~mm}$ getting an image in full size of $25 \mathrm{Mpx}$. The autofocus mode was used. The number of images is more important than necessary: this to permit a selection of images according to their quality, the purpose was here to acquire images in profusion rather than to have to return on site (still in other conditions). To guarantee the scaling of the models, scaling bars with coded targets were positioned around every block. For 200 blocks, more than 4000 images were taken in several campaigns (Diethrich, 2017).

\subsection{Unterlinden museum: an ideal environment}

The headstones were regularly arranged and spaced out in an intermediate storeroom where there were able to be recorded in very good conditions. Even if the number of images remains high - twice three series of approximately 40 images (Figure 6) - these were taken with a camera stabilized on a tripod. Exposure times (until 3 seconds) allowed to keep a depth of field recovering the largest part of every headstone. The diffuse and uniform lighting didn't cause a lot of shadow. The same scaling bars were arranged around each block for the scaling. A vertical recording (topview) was able to be added.

For 15 headstones parts, 3500 images were necessary and have been used for the modelling.

\subsection{Horbourg-Wihr}

The same method of photogrammetric modelling has been used there. The convergent images of the various blocks can be taken in the same conditions for both sides because blocks can have reversed directly. As they are stored onto wooden pallets, they are shielded from the humidity and their cleaning could be realized long time before. Blocks were thus available in ideal conditions. The outside environment is always coupled with luminosity problems, sun and shadows. Nevertheless, a rather fast recording allowed practically to free itself from these constraints. The same series of images were operated, the number of images was a little reduced for the general geometry of blocks, but was increased in the zones in which were engraved some writings. The same camera type was used, always with the same resolution and in autofocus mode. For 14 blocks, more than 1500 images were recorded to avoid a return on the site. Two different sets of scaling bars were arranged around each block for its scaling. For some blocks, the scaling bars were only used for the recording of first position (Face A).

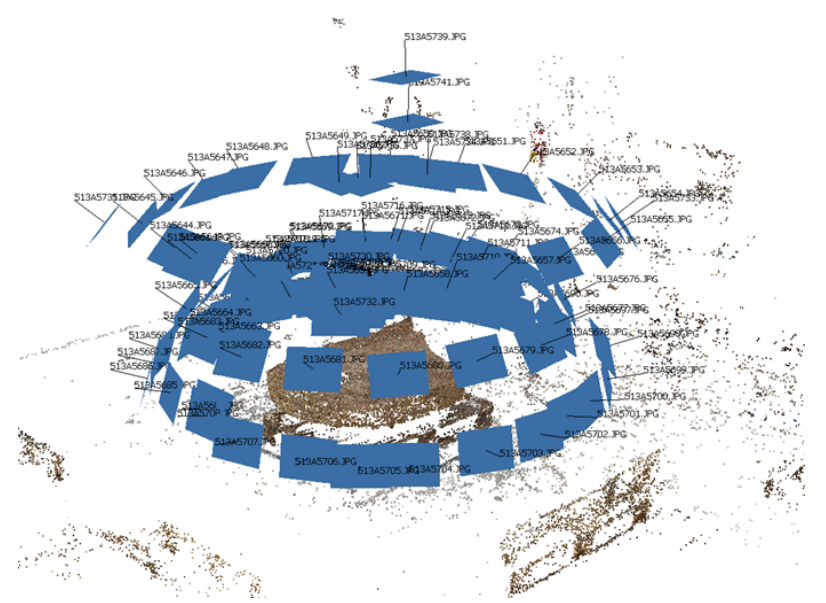

Figure 6: Illustration of image acquisition series for a block

\section{DIGITAL DATA PROCESSING}

Once the images have been acquired, data processing with Metashape produces half-models in the form of dense, exploitable point clouds that can be used to derive 3D models. The processing used for these 3D modelling was optimized according to the typology of blocks, to the density of the expected point clouds and to the expected geometrical accuracy.

The used sequence decomposes into several phases and uses several software:

Phase I (Agisoft Metashape):

- Sorting, quality checking and selection of the images

- Image alignment

- Target detection

- Scaling of the models

- Computing of initial point cloud

Phase II (Agisoft Metashape):

- Selection of a zone of interest

- Point cloud densification

- Export in .e57 format

The phase III consists of the 3D modelling in the 3DReshaper or CloudCompare software environment:

- Import .e57 files of both parts of every block

- Segmentation of block parts to be modelled

- Best-Fit adjustment

- Cleaning of residues

- Export in .las (or other) format

Two different ways of assembling the two faces of each block were used. The workflows i) using a best-fit adjustment of the two clouds (in 3DReshaper), ii) using the first face (A) cloud for referencing the second face (B) cloud (in Metashape or in 3DReshaper or in CloudCompare) are described in Figures 7 and 8. 


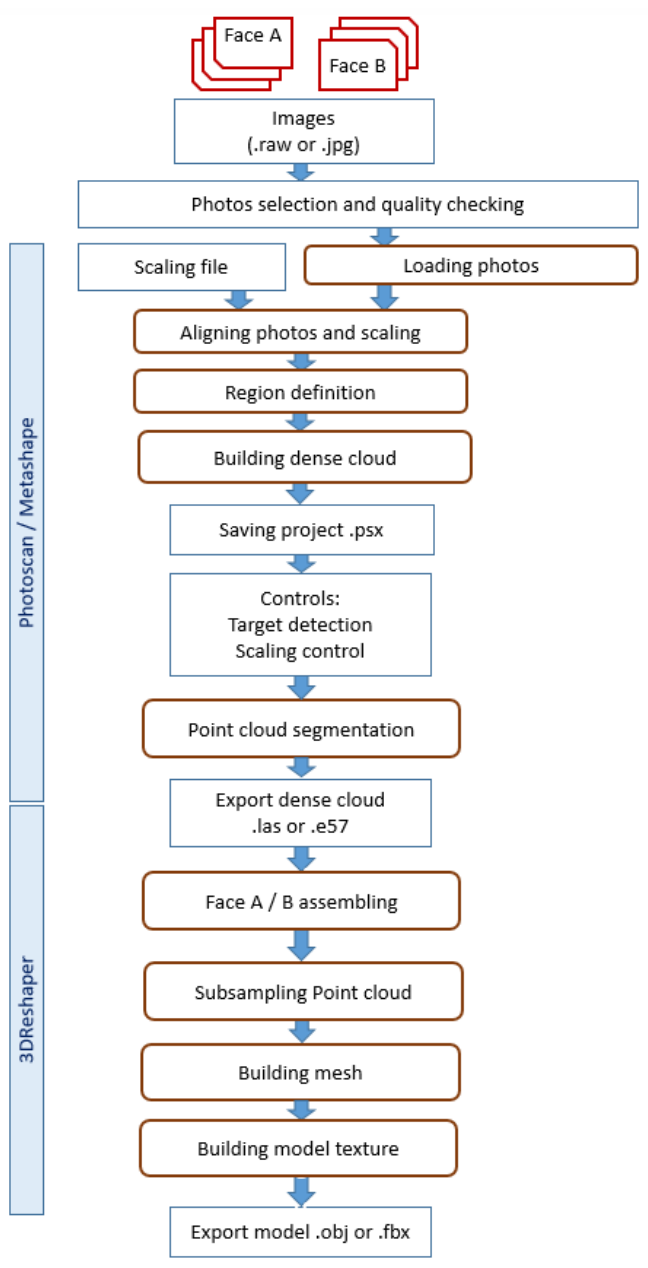

Figure 7: Workflow with assembling of two scaled faces using best-fit algorithm in 3DReshaper.

These various operations were partially automated in Python scripts and optimal parameters have been defined for every typology of block according to the expected results and given constraints.

Assessment: The cloud to cloud best-fit (3DReshaper) or align (CloudCompare) methods allow several quality checks of the models: i) the recognition of targets in different images and the use of scaling bars allow rigorous and independent dimensional controls. Both parts of the models are scaled independently. The results on target detections and readjustment using scaling bars give (considering all blocks in Sparsbach, for example) a mean rms value of about $0.2 \mathrm{~mm}$. Relative to the size of the modelled blocks, this accuracy was acceptable. The method using the resizing or the referencing of the second cloud based on the first cloud is therefore depending on the accuracy of the first cloud (Face A) obtained. It is then very dependent on the choice and definition of control points which must be identifiable in both clouds. This second method makes it possible to merge the two clouds of both sides A and B in a same Metashape project, which has other advantages especially in the further processing.

Consolidated point clouds can then be exported in different formats to be exploited according to initial needs and expectations.

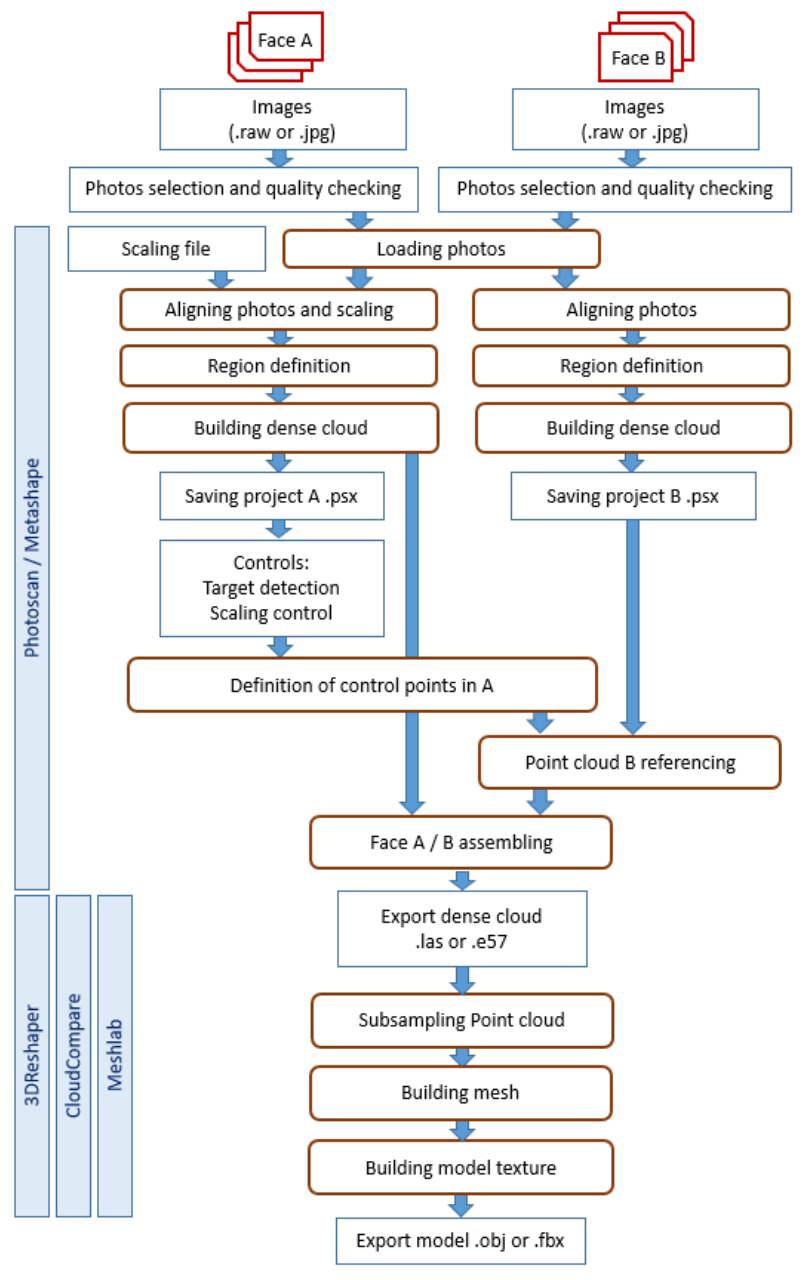

Figure 8: Workflow with assembling of two faces with one as reference and scaling unit using control points in Metashape.

\section{RESULTS AND UTILIZATION}

The final 3D models are based on very dense point clouds which can be adapted to the needs for utilization. With CloudCompare or by using a script in Meshlab, for example, the point clouds can be redeemed, on one hand by a determination of the normals, or by using distance between points as parameters.
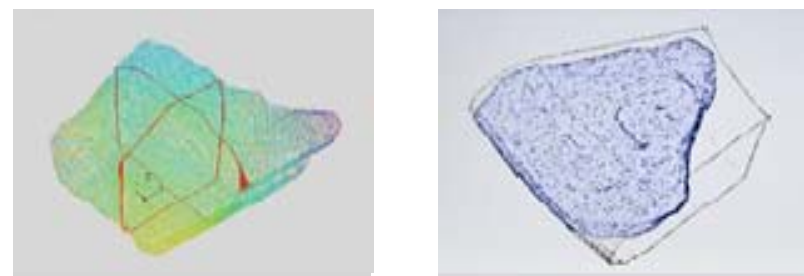

Figure 9: a- Extraction of characteristic profiles; b- Simulation of complete geometry from 3D model of artefact.

The resulting point cloud can then be meshed, and this mesh can be textured or rendered in other forms. The blocks were so able to be decomposed into sections and profiles allowing a fine analysis of the geometry of some typical architectural components of the antique period (Figures 9). 
The Meisenbachschloessel building was completely reconstructed by using the modelled blocks and by deducting the forms of the antique construction. The reconstruction so required the implementation of more than thousand blocks. (Figure 10 and 11).
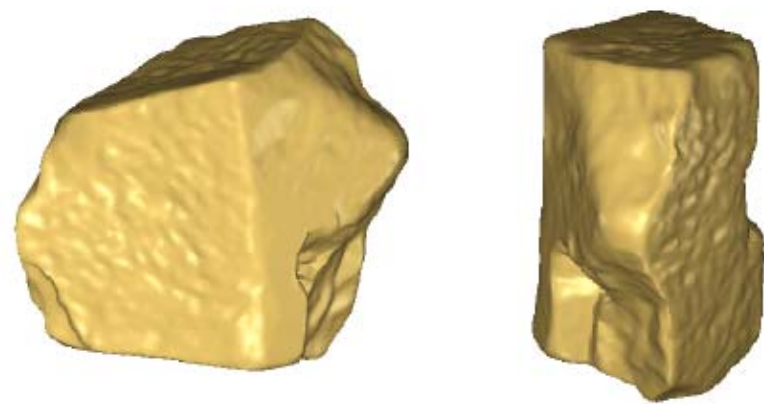

Figure 10: Mesh and neutral rendering of architectural blocks

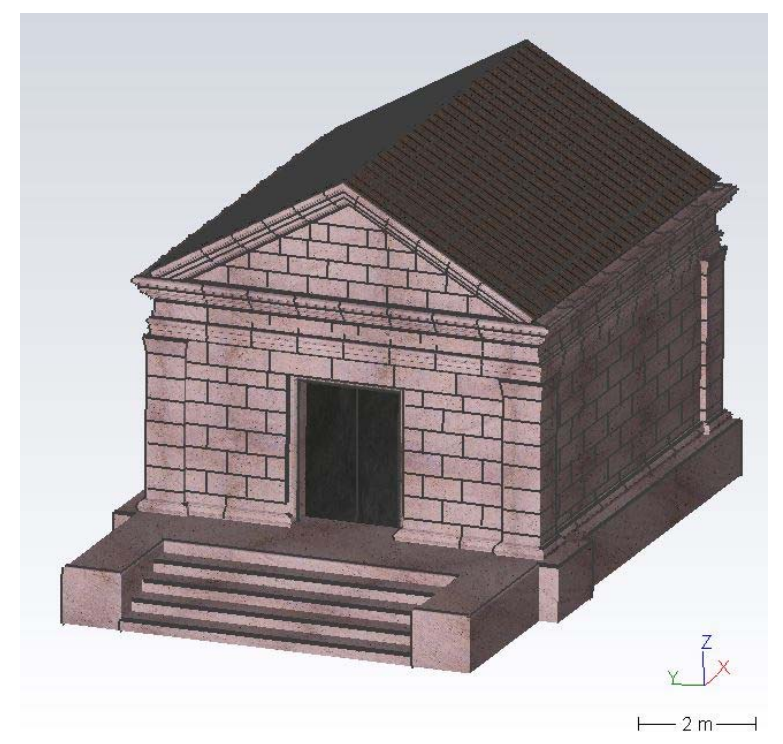

Figure 11: Reconstruction of Meisenbachschloessel from 3D modelled blocks

The antique blocks of Horbourg-Wihr are still the object of a thorough study. Even if blocks were only a few, their inscriptions were able to be clearly identified thanks to specific renderings of the $3 \mathrm{D}$ models. The identification of the original architectural structure is practically realized.

Once the 3D model was established, a PCV shading (CloudComlpare) was applied, with the aim of accurately highlighting the tool tracks and writings. The PCV algorithm is simulating the 'natural' illumination of the scene as if there were spotlights sampled all over an hemisphere or a sphere (the cloud lying at the centre of this sphere).

Here the contrast made the epigraphic letters perfectly legible, allowing to discriminate the traces of tools related to the size and shaping of the block from those that correspond to the work of the engraver. The example block no. 6 allowed to search for letters and isolate words separated by punctuation. The letter size depth is much greater than the tool marks of the block shaping and an enlargement allowed to differentiate the tools used (Figure 12). In addition, the 3D model showed a slight curvature of the block, which certainly corresponds to its integration in the semi-circular row of the stands of an antique theatre (Figure 13).
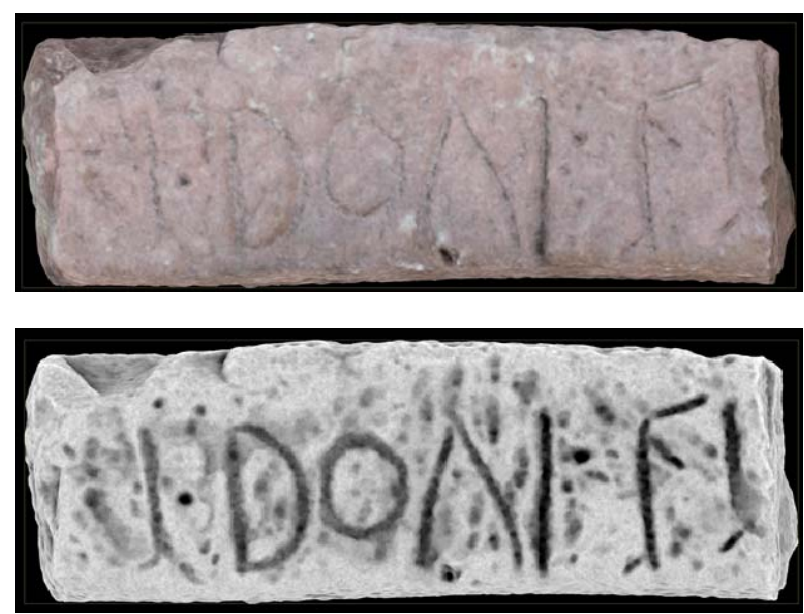

Figure 12: 3D modelling of block $n^{\circ} 6$ (Face 1 ) and its PCV rendering.

The opposite face (Face 3) of the same block was partially covered with lime mortar, suggesting other inscriptions. The applied PCV processing made it possible to make readable new letters, whose size and type showed that it is another writing than that of Face 1.
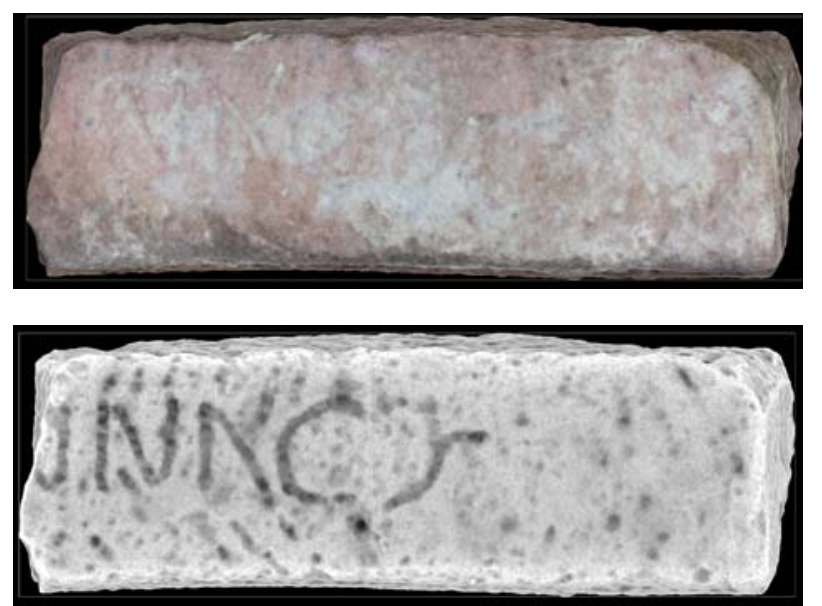

Figure 13: Opposite face of block $n^{\circ} 6$ (Face 3 ) and its PCV rendering.

The Gallo-Roman headstones were able to be reassembled virtually. Profiles and sections were able to be extracted what allowed to know them better and to understand the symbolism of the ornaments.

Below, the complete workflow (in Metashape) for processing headstones followed by some examples of applications are given. Among the applications we can mention particular renderings with or without texture, with illuminations allowing to bring out details or even particular writings (CloudCompare) (Figure 14 and 15). Also upon request the extraction of sections were used to quantify and measure geometric elements in the blocks (CloudCompare or Meshlab). A third application also concerns the generation of animations (CloudCompare) which for the blocks consisted either of zooming in on particular details or of rotating the blocks to understand their shape, geometry and possibly composition. Finally, special renderings permitted the extraction of characteristic lines, for example, which can be used as contour generators. 

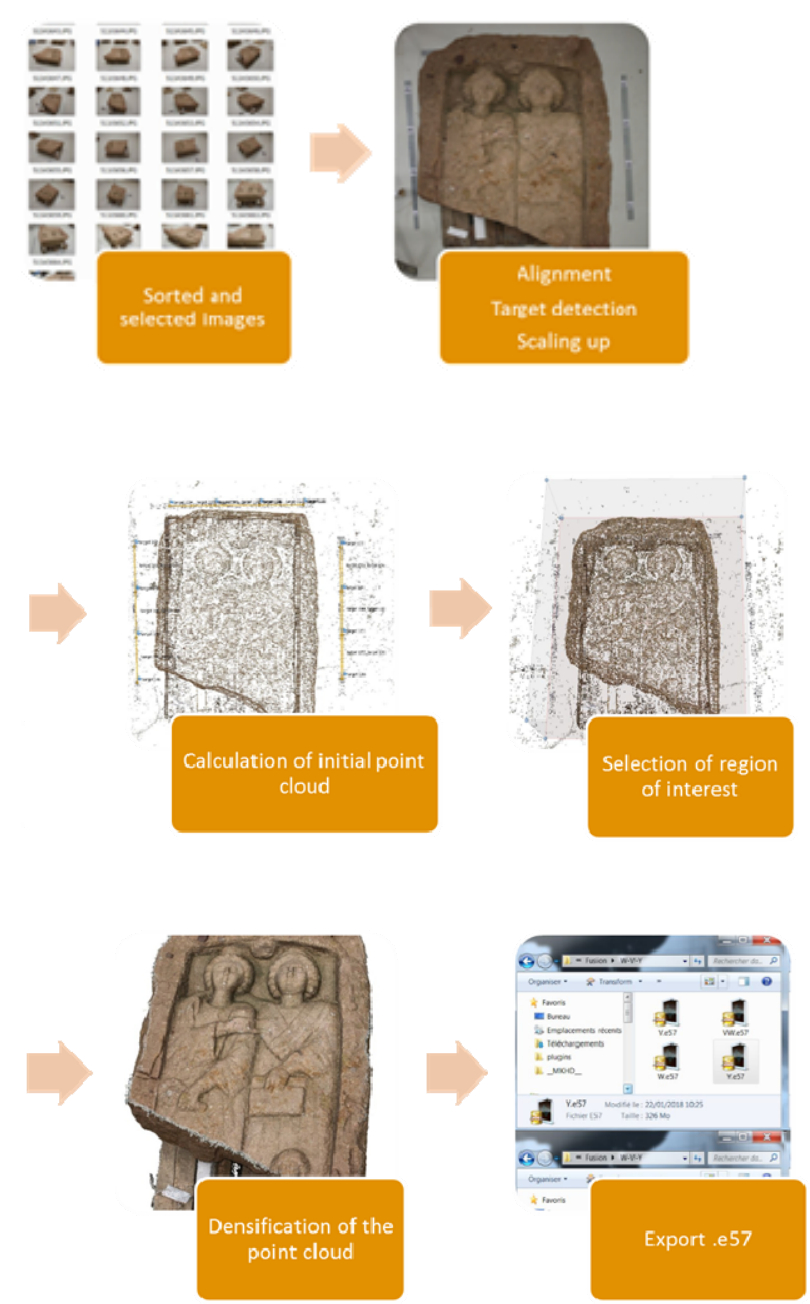

Figure 14: Workflow in Metashape

It was also possible to digitally reconstruct the headstones that are unfortunately fractured today. Digital reconstitution made it possible to confirm more delicate physical reconstitutions with blocks weighing several hundred kg (Figure 16).
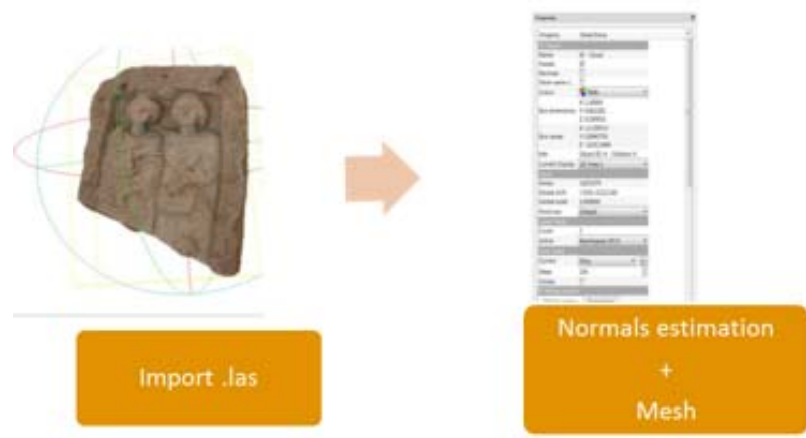
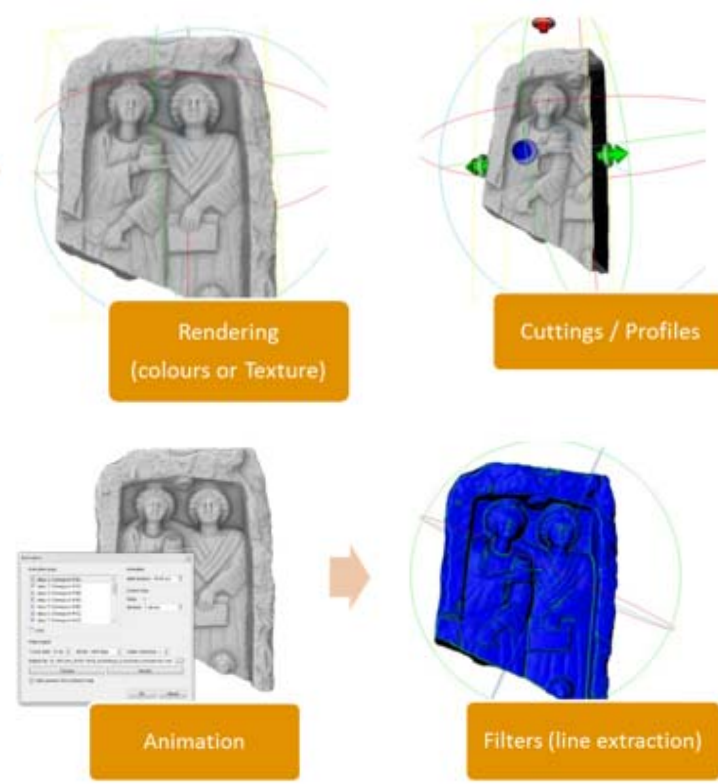

Figure 15: CloudCompare rendering, section, animation and line extration.
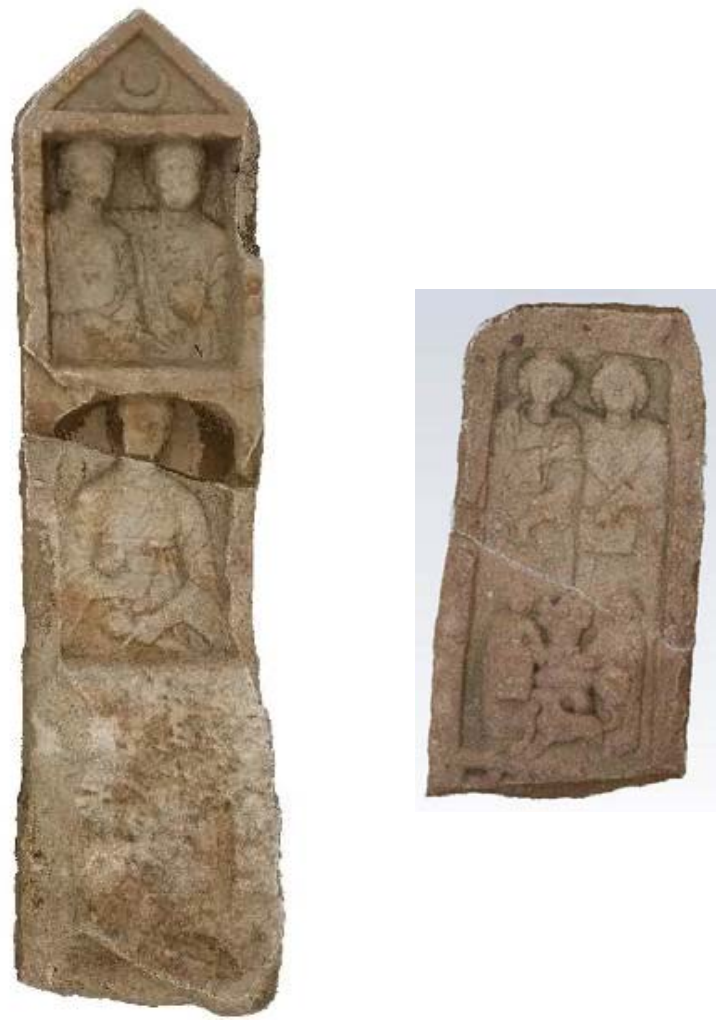

Figure 16: Reconstruction of broken headstones

\section{CONCLUSION}

The photogrammetric methodology of recording and modelling of blocks was able to be adapted to the various typologies of blocks according to the results and the expected models. These 3D models were then used for the promotion and the archiving of elements. The blocks of Meisenbachschloessel were buried on the site to guarantee their conservation. The very faithful 3D models allowed to lead more ample investigations by using 
virtual tools. As explained, the antique blocks of HorbourgWihr were still the object of a thorough study. The antique headstones of Niederhergheim will be exposed in Museums. But it will also be valued, consulted and analysed thanks to virtual tools and to the quality of the generated 3D models.

Through these three examples, the demonstration has been made that photogrammetry is particularly suitable, offering flexibility, time saving, and adapting to both outdoor and diverse conservation environments.

3D modelling is used for the implementation of measures and allows to preserve the original blocks, to limit their manipulation and to access a fine level of micro-relief reading and analysis. The acquisition and processing method is lowcost, even if it requires significant computing power.

Finally, the 3D objects modelled in this way allow an easy dissemination of information to the research community, but also the possibility of integrating it into cultural mediation and heritage enhancement schemes. For archaeologists, these techniques offer an alternative that is more efficient, more exhaustive and more relevant than traditional surveys.

\section{ACKNOWLEDGEMENTS}

Here we would like to thank L. Barrand and J. Diethrich who have been actively involved in the various field acquisition campaigns and in the automation of certain parts of the process, as well as S. Guillemin (INSA Strasbourg) who participated in the different analysis phases, F. Basoge (Archéologie Alsace) who realized the PCV renderings and S. Blin (CNRS/ENS) for scientific interpretation.

\section{REFERENCES}

Adamopoulos, E., Tsilimantou, E., Keramidas, V., Apostolopoulou, M., Karoglou, M., Tapinaki, S., Ioannidis, C., Georgopoulos, A., Moropoulou, A., 2017. Multi-sensor documentation of metric and qualitative information of historic stone structures. In: ISPRS Annals of the Photogrammetry, Remote Sensing and Spatial Information Sciences, Volume IV2/W2, pp. 1-8, doi.org/10.5194/isprs-annals-IV-2-W2-1-2017.

Archéologie Alsace, 2019. Archéologie Alsace web site: https://www.archeologie.alsace/ (20 february 2019).

Bonneterre, D., Rémy, J., Triantafillidis, G., Waton, M.-D., 2012. À propos d'une des stèles funéraires romaines découvertes à Niederhergheim (Haut-Rhin). Cahiers Alsaciens d'Archéologie d'Art et d'Histoire, tome LV, pp.27-32, Strasbourg.

Calisi, D., 2016. Photogrammetric survey and 3D modeling of the funerary urn depicting the Myth of Oenomaus, found inside the tomb of the Etruscan Family of Cacni in Perugia (III-I Century BC). In: International Congress on Archaeology, Computer Graphics, Cultural Heritage and Innovation 'ARQUEOLÓGICA 2.0', pp. 95-104, dx.doi.org/10.4995/ arqueologica8.2016.33.

Diethrich, J., 2017. Modélisation tridimensionnelle du monument antique du Meisenbachschloessel de Sparsbach (Bas-Rhin). Master thesis, INSA Strasbourg, 104 pages.

Fuchs, A., Alby, E., Begriche, R., Grussenmeyer, P., and Perrin, J.-P., 2004. Confrontation du relevé laser 3D aux techniques de relevé conventionnelles et de développement d'outils numériques pour la restitution architecturale. In: Revue
Française de Photogrammétrie et de Télédetection, (174), pp.36-47, halshs.archives-ouvertes.fr/halshs-00260671

Fuchs, M., 1996. Horbourg-Wihr à la lumière de l'archéologie, Histoire et nouveautés, Mélanges offerts à Charles Bonnet. Actes II d'ARCHIHW, Horbourg-Wihr, 1996, 222 pages.

Fuchs, M., 2019. Horbourg-Wihr, Hinter den Gaerten, Hypothèse d'un théâtre gallo-romain précédant des châteaux, Sélestat, 2019 to be published.

Fuchs, M., Meyer, N., 2019. Le Meisenbachschloessel à Sparsbach, un monument romain dans les Vosges du Nord, Sélestat, 2019 to be published, 32 pages.

Grussenmeyer, P., 2003. Photogrammétrie architecturale et modélisation 3D du patrimoine. In: Revue $X Y Z \mathrm{n}^{\circ}$ 95, pp. 30-36, ISSN 0290-9057.

Hayes, J., Fai, S., Kretz, S., Ouimet, Ch., White, Ph., 2015. Digitally-Assisted Stone Carving of a Relief Sculpture for the Parliament Buildings National Historic Site of Canada. In: ISPRS Annals of the Photogrammetry, Remote Sensing and Spatial Information Sciences, Volume II-5/W3, pp. 97-103, doi.org/10.5194/isprsannals-II-5-W3-97-2015.

Landes, T., Waton, M.-D., Alby, E., Gourvez, S. and Lopes, B., 2013. 3D Modelling of headstones of the 2nd and 3rd century by low cost photogrammetric techniques. In: International Archives of the Photogrammetry, Remote Sensing and Spatial Information Sciences, Volume XL-5/W2, pp. 397-402, doi.org/10.5194/isprsarchives-XL-5-W2-397-2013.

Marc, J.-Y., Fuchs, M. (dir.), Blin, S., Flotté, P., Fortuné, C., Freyssinet, E., Meyer, N., Michler, M., Roux, R., Schmidt, K., 2005. Sparsbach, Bas-Rhin, « Meisenbachschloessel », Rapport de campagne 2005, Rapport de fouille programmée, Strasbourg, 2 vol., 94 pages.

Marc, J.-Y., Fuchs, M. (dir), Blin, S., Flotté, P., Fortuné, C., Gervreau, J.-B., Meyer, N., Michler, M., Roux, R., 2006. Sparsbach, Bas-Rhin, "Meisenbachschloessel », Rapport de campagne 2006, Rapport de fouille programmée, Strasbourg, 2 vol., 78 pages.

Pavlidis, G., Koutsoudis, A., Arnaoutoglou, F., Tsioukas, V., and Chamzas, C., 2007. Methods for 3D digitization of Cultural Heritage. Journal of Cultural Heritage, (8): pp. 93-98.

Santagati C., Lo Turcob, M., Bocconcino, M., Donat, V., Galiziaa, M., 2017. 3D models for all: low-cost acquisition through mobile devices in comparison with image based techniques. Potentialities and weaknesses in cultural heritage domain. In: International Archives of the Photogrammetry, Remote Sensing and Spatial Information Sciences, Volume XLII-2/W8, pp. 221-228, doi.org/10.5194/isprs-archives-XLII2-W8-221-2017.

Scholz, M., 2012, Grabbauten des 1.-3. Jahrhunderts in den nördlichen Grenzprovinzen des Römischen Reiches. Römische Germanische Zentral Museum, Monographie, $\mathrm{n}^{\circ} 103$, Mainz, 2012, 2 Bände, 1140 pages. 